\title{
THE FAUNAL ASSEMBLAGE IN FRESHWATER CRAYFISH BURROWS IN SEDGELAND AND FOREST AT LIGHTNING PLAINS, WESTERN TASMANIA
}

\author{
by Pierre Horwitz and Brenton Knott
}

(with one table and one text-figure)

\begin{abstract}
HORWITZ, P. \& KNOTT, B., 1991 (20:xii): The faunal assemblage in freshwater crayfish burrows in sedgeland and forest at Lightning Plains, western Tasmania. Pap. Proc. R. Soc. Tasm. 125: 29-32. https://doi.org/10.26749/rstpp.125.29

ISSN 0080-4703. Department of Geography and Environmental Studies, University of Tasmania, GPO Box 252C, Hobart, Tasmania, Australia 7001; and Department of Zoology, University of Western Australia, Nedlands, WA, Australia 6009.
\end{abstract}

\begin{abstract}
The faunal assemblage of crayfish burrows was examined intensively at Lightning Plains in western Tasmania, in sedgeland and adjacent forest, to determine variations in species occurrences and abundances both within one habitat type and between two habitatts. Species-sample curves showed that over $90 \%$ of the species found in ten samples could be collected by taking only five. Despite the fact that the host crayfish species was the same, each habitat was found to display a characteristic assemblage. Variations between the assemblages are attributed to differences in soil conditions, vegetation structure and watertable behaviour.
\end{abstract}

Key Words: Western Tasmania, invertebrates, crayfish, burrows, pholeteros.

\section{INTRODUCTION}

Previous investigations of the freshwater fauna in crayfish burrows of western Tasmania (Lake \& Newcombe 1975, Suter \& Richardson 1977, Horwitz 1989) or elsewhere in southeastern Australia (Horwitz et al. 1985, Boulton 1989) have used "snapshot" sampling events and substantial information has been gained from this approach. The "pholeteros" (sensu Lake 1977) is now known to include diverse crustacean and oligochaete faunas, as well as nematodes, dipteran and other insect larvae, with up to 20 species in any one burrow system. However, snapshot sampling events can only record species occurrences in the particular time and season available for sampling, under the climatic conditions on the day. Also, variations of habitats potentially capable of harbouring rare species have not, so far, been analysed systematically and quantitatively. This paper aims to correct this omission, at least partially, by examining the variation in the occurrence of species in the pholeteros from burrow to burrow within a site on a single occasion. Another aim is to determine whether the fauna varies between sites with different microhabitats. In doing so, it was hoped to estimate the number of samples required to collect a major proportion of the species of pholeteros in an identifiable habitat type at any one time.

\section{METHODS}

The examination of pholeteros was conducted at Lightning Plains, a flat area in the headwaters of the Jane River, just south of Frenchmans Cap in western Tasmania, lying at an altitude of $360-400 \mathrm{~m}$. Despite their simple topography, the plains exhibit a heterogeneous set of geological, pedological and hydrological conditions, and this characteristic of Lightning Plains gave us an opportunity to examine the variation of pholeteros in different habitats. Within a relatively small distance (200-300 m), two distinct crayfish burrow habitats occurred: on the western side of a low dolomite ridge was a buttongrass plain (sedgeland) and immediately east of the ridge was mixed forest.
The sedgeland site was dominated by grasses, herbs and shrubs, including Gymnoschoenus sphaerocephalus (R.Br.) Hook.f. (buttongrass), Restio spp., Xyris sp., Leptocarpussp., Melaleuca squarrosa Donn ex Smith, Callistemon sp. and Leptospermum sp., on soils composed of shallow peats (50 $150 \mathrm{~mm}$ ) overlying silty sand on quartzitic gravel. The "Forest" site occurred on a claypan (impeded drainage) and burrows were constructed in grey-brown, silty loamy clay soils, where the vegetation was dominated by a Eucalyptus nitida Hook.f. overstorey with Leptospermum sp. and Nothofagus cunninghamii (Hook.) Oersted in a lower stratum; Gahnia grandis (Labill.) S.T.Blake and Blechnum nudum (Labill.) Mett. ex Luerss were the dominant components of the ground stratum. The water in the burrows at both sites had $\mathrm{pH}$ values of between 3.8 and 5.8.

All fieldwork was undertaken in late January 1989, when helicopter transport was available; it was not possible to resample in this remote locality. The techniques involved to collect, preserve and analyse samples were the same for the two sites.

The freshwater crayfish Parastacoides tasmanicus inermis (Clark) occurred at both sites. At the forest site a further two species were located, Astacopsis franklinii (Gray) and Engaeus cisternarius Suter, but by far the most abundant species was $P$. t. inermis. In sampling the pholeteros, burrows with similar-looking surface openings were selected in order to ensure that a maximum number of $P$. $t$. inermis burrows were analysed (rather than those of the other species). Thus, at both sites the structure of burrows sampled was similar, with usually two $\bullet$ r three entrances converging to form one descending tunnel to $0.35-0.60 \mathrm{~m}$ depth, where the burrow terminated in a slightly enlarged chamber.

In each burrow the watertable was carefully exposed by removing the chimney of soil thrown up by the crayfish and the surface portions of the soil around the burrow. All water was completely removed from the burrow by inserting a siphon (10 $\mathrm{mm}$ internal diameter) and sucking it out; the water (containing the pholeteros) was then passed through a sieve $(0.05 \mathrm{~mm}$ mesh-pore size). Whilst volumes were not measured in the field, most samples represented at least $\bullet$ ne litre, and there were no gross differences between the volumes 
of burrows at each site. The sieved fraction remaining was preserved in $5-10 \%$ formalin in a plastic bag. The collecting equipment was thoroughly cleaned in filtered water between eac h sample to prevent contamination of subsequent samples.

Ten samples were taken from each site, with each sample rep resenting a separate burrow system. Crayfish (either juveniles or adults) were found in all but three of the burrows sampled (two from sedgeland and one from forest); the crayfish were identified in situ and generally not collected.

In the laboratory, samples were washed through sieves of mesh-pore sizes $1 \mathrm{~mm}, 0.5 \mathrm{~mm}$ and $0.25 \mathrm{~mm}$. (Animals capable of passing through a pore size of $0.25 \mathrm{~mm}$ were the refore not likely to have been detected.) Washed samples were sorted under a low-power dissecting microscope.

Collected taxa were identified to species level where possible, and placed into one of three groups:

(1) terrestrial species which are known to occur in leaf litter or the soil; these were assumed to be fall-ins;

(2) those species which are known to be symbiotic or commensal on freshwater crayfish (including temnocephalan flatworms and entocytherid ostracods); and

(3) "true" members of the pholeteros.

Only data from this third group were analysed further. Each species per sample was assigned an abundance value: absent, rare (one individual only), few ( $2-10$ individuals) and common (more than 10 individuals). Species-sample curves were constructed for each site using presence-absence data. The data were classified using the polythetic divisive computer programme TWINSPAN (Hill 1979), taking abundance classes as cut levels.

\section{RESULTS}

Species of invertebrates which were deemed to be terrestrial included frve species of terrestrial mites, one species of Opilionidae, paronellid collembolans, earthworms, an oniscid isopod (Styloniscussp.) and one adult curculionid coleopteran. These species were excluded from the analysis presented below.

Twenty-seven taxa were recognised as being true components of the pholeteros. Of these, 24 were found in burrows in the sedgeland area, with between 8 and 15 species in individual samples. For the forest site, 19 species were identified, with between 5 and 12 species from each burrow. Species-sample curves (cumulative frequency plots - fig. 1) show that over $90 \%$ of the species in sedgeland burrows are found in the first five samples and $100 \%$ of all species were found in the first five samples in forest burrows.

The species found in this survey are given in table 1 , showing two TWINSPAN groups; the level of division used was the first division, justified by the small number of samples and species. The twenty samples were split into one group of eight, comprising only samples from forest burrows, and one group of twelve. In the latter group, both of the forest burrow samples (numbers 14 and 16 , table 1) were borderline in the division and were also allied to the forest group. Therefore, the division clearly separated forest burrows from sedgeland burrows on the basis of the faunistic abundance data. Important indicator taxa for this division included the oligochaete species 4 and 5, chironomid (Orthocladiinae) larvac and the cyclopoid copepods Acanthocyclops sp. nov. and Diacyclops cryonastes Morton. The cyclopoid species are important in terms of their abundances, with Acanthocyclops sp. nov. more abundant

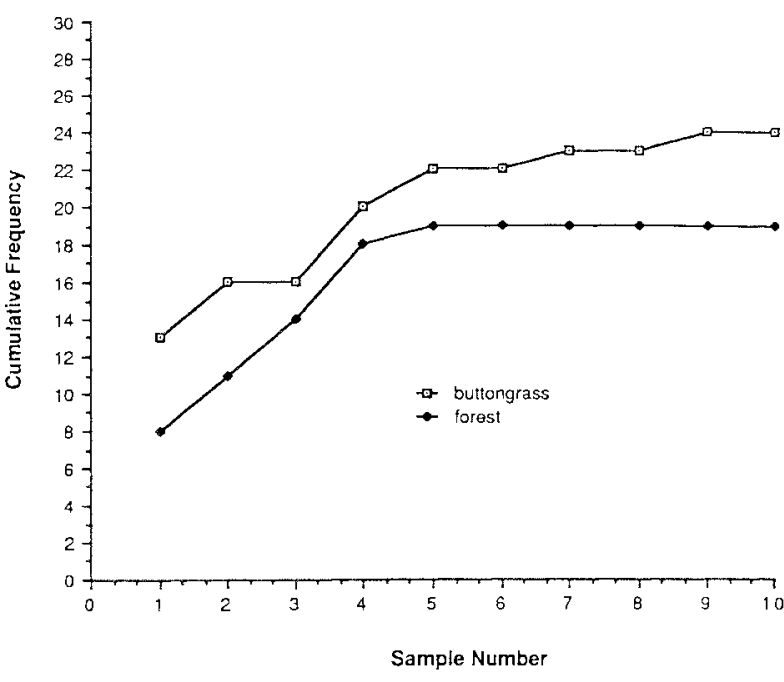

FIG. I - Typical cumulative frequency plots of the number of species found in each sample at each site (presented in the order in which they were collected).

than $D$. cryonastes in sedgeland burrows, and vice versa for forest burrows.

Sixteen taxa were found in samples at both sites. Of these, eight taxa might be regarded as commonly occurring at both sites: the nematodes, the ostracod Candona nr. tecta, the two cyclopoid copepods, the harpacticoid copepod Canthocamptus sp., amphipod Neoniphargus nr. tasmanicus, the janirid isopod ?Heteriassp. and the oligochaete Phreodrilus proboscidea Brinkhurst and Fulton.

Eleven species were restricted to one or the other site: eight species were found only in sedgeland burrows while three were restricted to burrows in forest.

\section{DISCUSSION}

The composition of the pholeteros at Lightning Plains is essentially similar to that which one would expect to find elsewhere in southwestern Tasmania (see Horwitz 1989), although the absence of syncarid and phreatoicid crustaceans is intriguing, at least from a zoogeographical point of view. The finds of cladocerans, gastropods and an odonatan are new records for the faunal assemblage of crayfish burrows.

The species-samples curves show that over $90 \%$ of the fauna available in ten samples could be collected by taking only five, and 1 or 2 samples will collect at least $50 \%$ of the faunal assemblage. The sampling technique used in this survey sampled each burrow completely by removing all burrow water. At other sites it may not be possible to completely empty (or sieve) all the burrow water and this could well result in an inability to collect rarer species; under these conditions larger numbers of samples may be needed to obtain representativeness.

The higher species richness in sedgeland burrows compared to that in forest burrows may be due to an interaction between two related characteristics of sedgeland areas, namely organic rich soil (peat) and a high watertable. The presence of peat could in theory provide proportionately larger amounts of nutrient (in the form of organic soil particles and associated microbial flora), compared to the relatively inert mineral soils in the forest. The presence of a watertable 
TABLE 1

TWINSPAN results showing the species found in each sample (where samples are numbered from 1-10 for buttongrass, and 11-20 for forest), the division recognised by TWINSPAN at the first level, and the species divisions at the first level. Abundance values for each species present in each sample $(1,2$ or 3$)$ are explained in the text.

\begin{tabular}{|c|c|c|c|c|c|c|c|c|c|c|c|c|c|c|c|c|c|c|c|c|c|c|}
\hline & Sample number & 4 & 5 & 6 & 9 & 10 & 3 & 7 & 1 & 2 & 8 & 14 & 16 & 13 & 17 & 20 & 11 & 19 & 12 & 15 & 18 & $\begin{array}{c}\text { Species } \\
\text { Divisions } \\
\text { (1st Level) }\end{array}$ \\
\hline Class/Order & Species & & & & & & & & & & & & & & & & & & & & & \\
\hline OLIGOCHAETA & Oligochaete sp. 3 & & & & & & & & & 1 & 1 & & & & & & & & & & & 0 \\
\hline AMPHIPODA & Neoniphargus nr. spenceri & & & & & & & 2 & & & & & & & & & & & & & & 0 \\
\hline DIPTERA & Tabanidae (larvae) & & & & 1 & & & & 1 & & 1 & 1 & & & & & & & & & & 0 \\
\hline CLADOCERA & Bosmina sp. & 1 & & & & 2 & & & 1 & & & 2 & & & & & & & & & & 0 \\
\hline GASTROPODA & Glacidorbis sp. & 2 & 3 & 3 & & 2 & & 2 & & & & & & & & & & & & & & 0 \\
\hline OSTRACODA & Cyprididae sp. nov. & & 3 & 3 & 1 & 3 & & 3 & & & 1 & & & & & & & & & & & 0 \\
\hline DIPTERA & Orthocladinae (larvae) & 2 & 2 & 1 & 2 & 1 & & & & 2 & 2 & & & & & & & & & & & 0 \\
\hline ODONATA & Synthemis macrostigma orientalis & 1 & & & & & & & & & & & & & & & & & & & & 0 \\
\hline DIPTERA & Ceratopogonidae (larvae) & & 2 & & 1 & & & & & & & & & & & & & & & & & 0 \\
\hline DIPTERA & Culicini (larvae) & 2 & 2 & 1 & 1 & 1 & & & 1 & & 1 & & & & & & & & & 3 & & 0 \\
\hline DIPTERA & Orthocladiinae (pupae) & & 2 & 2 & & & & & & 1 & & & & & & & & & & & & 0 \\
\hline COLEOPTERA & Helodidae (larvae) & & & & & & & 1 & 1 & 1 & & 1 & & & & & & & 1 & & & 0 \\
\hline COPEPODA & Acanthocyclops sp. nov. & 3 & 3 & 3 & 2 & 3 & 3 & 3 & 3 & 2 & 3 & 2 & & 2 & 2 & & 2 & 2 & 2 & & & 1 \\
\hline NEMATODA & Nematoda sp. or spp. & 2 & 2 & 3 & 3 & 3 & 3 & 3 & 2 & 3 & 2 & 2 & 1 & 2 & 2 & 2 & & 2 & 3 & & 2 & $!$ \\
\hline OLIGOCHAETA & Oligochaete sp. 2 & & 1 & 1 & 1 & 1 & 1 & 1 & 1 & 1 & 1 & & & 1 & & 1 & 1 & & 1 & & & 1 \\
\hline OSTRACODA & Candona_nr._tecta & 3 & 3 & 3 & 2 & 3 & 3 & 3 & 3 & 3 & 3 & 3 & 2 & 3 & & & 3 & 3 & 3 & 3 & & 1 \\
\hline COPEPODA & Canthocamptus sp. & 1 & 2 & 3 & 1 & 1 & 2 & 2 & 1 & 1 & & 2 & & 2 & 1 & 1 & 1 & 1 & & & & 1 \\
\hline AMPHIPODA & Neoniphargus nr. tasmanicus & & & 3 & 2 & 3 & 3 & 3 & 3 & 2 & 3 & 3 & 2 & 2 & & 2 & 1 & 3 & 3 & 3 & & 1 \\
\hline ISOPODA & ? Heterias sp. & 1 & & 3 & 3 & 3 & 3 & 3 & 3 & 2 & 3 & 3 & 2 & 3 & & & 3 & 3 & 3 & 3 & & 1 \\
\hline COPEPODA & Diacyclops cryonastes & 2 & 3 & & 1 & 2 & 2 & 2 & 3 & 2 & 3 & 2 & 2 & 3 & 3 & 1 & 3 & 3 & 3 & 3 & 3 & 1 \\
\hline OLIGOCHAETA & Phreodrilus probiscidea & & & 1 & & & & & 1 & 1 & & 1 & & & 1 & 1 & 1 & & 1 & 2 & & 1 \\
\hline DIPTERA & Limoniinae (larvae) & & & & 1 & & & & & & & & & & & & & & 2 & & 1 & 1 \\
\hline DIPTERA & Unidentified lanvae sp. 3 & & & & & & & & & & & 1 & & & & & & & & & 1 & 1 \\
\hline OLIGOCHAETA & Oligochaete sp. 4 & 1 & & & & & & & & & & & & 1 & 1 & & & & 1 & 1 & 1 & 1 \\
\hline OLIGOCHAETA & Oligochaete so. 5 & 1 & & & 1 & & & & & & 1 & & & 1 & 1 & 1 & & & & 1 & 1 & 1 \\
\hline DIPTERA & Unidentified larvae so. 1 & & & & & & & & & & & & 1 & 1 & & & & & & & & 1 \\
\hline \multirow[t]{4}{*}{ DIPTERA } & Unidentified larvae sp. 2 & & & & & & & & & & & & & 2 & & & & & & & & 1 \\
\hline & & & & & & & & & & & & & & & & & & & & & & \\
\hline & TWINSPAN Division (1st Levei) & 0 & 0 & 0 & 0 & 0 & 0 & 0 & 0 & 0 & 0 & 0 & 0 & 1 & 1 & 1 & 1 & 1 & 1 & 1 & 1 & \\
\hline & TOTAL NUMBER OF SPECIES & 13 & 12 & 13 & 15 & 13 & 8 & 12 & 13 & 13 & 13 & 12 & 5 & 12 & 8 & 7 & 10 & 8 & 10 & 8 & 6 & \\
\hline
\end{tabular}


in the peat makes the peat available to the pholeteros by providing a water continuum between the space in the burrow and the spaces in the soil. (During the sampling of burrows, after water was extracted from burrows in sedgeland, they refilled relatively quickly, whilst those in the forest refilled either very slowly or not at all.) Sedgeland burrows are therefore part of a much larger reservoir of water which occupies the interstitial spaces in the peats and below.

Furthermore, watertable fluctuations in sedgeland areas are likely to be greater in amplitude because the more exposed conditions lead to greater evapo-ttanspiration in summer, amongst other things. Ar the end of summer, when the site was visited, the numerous pools on the surface in the sedgeland were all dry. The presence of surface pools may well explain the better representation of chironomids, culicids and ceratopogonids in sedgeland; these insects deposit eggs in the pools, and then larvae and pupae are forced to over-summer in burrows as they follow the watertable. The ability of crayfish burrows to carry a temporary freshwater fauna thtough summer has been noted before (for instance Williams et al. 1974). This may be another reason for higher species richness in sedgeland burrows and the larger numbet of samples tequited to collect all identified species, compated to the forest, where no surface depressions or pools were apparent.

Finally, it should be remembered that species symbiotic or parasitic on crayfish have been removed from the analysis. Furthet disctiminatory data may be available to characterise eithet microhabitat variation within one site or variation between habitats by examining this collection of species. For instance, the ectocommensal temnocephalan species Temnocephala ?cita was found on ctayfish from sedgeland burrows whilst $T$. ?pygmaea was found on the same crayfish host from forest burrows.

\section{ACKNOWLEDGEMENTS}

This project was funded by the Tasmanian Department of Parks, Wildlife and Heritage as part of the World Heritage Area Directed Wildlife Research Program in 1989. We are grateful to Stuart Halse and Dave Morton for assistance in the identification of ostracods and cyclopoid copepods respectively. Rod Fensham and Jennie Whinam assisted in the application and interpretation of TWINSPAN. Alastair Richardson made useful comments on the manuscript twice and idenrified the crayfish belonging to the genus Parastacoides.

\section{REFERENCES}

Bouliton, A.J., 1989: Over-summering refuges of aquatic macroinvertebrates in two intermittent streams in central Victoria. Trans. R. Soc. SA 113: 23-34.

HIL, M.O., 1979: TWINSPAN - A FORTRAN PROGRAM FOR ARRANGING MULTIVARIATE DATA INA TWO-WAY TABLE BY CLASSIFICATION OF INDIVIDUALS AND ATTRIBUTES. Cornell University, Ithaca.

HoRwIT', P., 1989: The faunal assemblage (or pholeteros) of some freshwater crayfish burrows in southwest Tasmania. Bull. Aust. Soc. Limnol. 12: 29-36.

Horwitz, P., Richardoson, A.M.M. \& Boulton, A.J., 1985: The burrow habitat of two sympatric species of land crayfish, Engaeus urostrictus and E. tuberculatus (Decapoda: Parastacidae). Vict. Nat. 102: 188-197.

LAKE, P.S., 1977: Pholeteros - the faunal assemblage found in crayfish burrows. Aust. Soc. Limnol. Newsl. 15: 57-60.

LaKE, P.S. \& NewCOMBE, K.J., 1975: Observations on the ecology of the crayfish Parastacoides tasmanicus (Decapoda; Parastacidae) from south-western Tasmania. Aust. Zool. 18 : 197-214.

Suter, P. \& Richardoson, A.M.M., 1977: The biology of two species of Engaeus (Decapoda: Parastacidae) in Tasmania III. Habitat, food, associated fauna and distribution. Aust. J. Mar. Freshw. Res. 28: 95-103.

Williams, D.D., Williams, N.E. \& Hynes, H.B.N., 1974: Observations on the life history and burrow construction of the crayfish Cambarus fodiens (Cortle) in a temporary stream in southern Ontario. Can. J. Zool. 52: 365-370.

(accepted 3 May 1991) 